\title{
Rhodium-catalyzed carbonylative arylation of alkynes with arylboronic acids: an efficient and straightforward method in the synthesis of 5-aryl-2(5H)-furanones $\dagger$
}

\author{
Özge Aksın, ${ }^{a}$ Nurcan Dege, ${ }^{a}$ Levent Artok, ${ }^{* a}$ Hayati Türkmen ${ }^{b}$ and Bekir Çetinkaya ${ }^{b}$ \\ Received (in Cambridge, UK) 10th May 2006, Accepted 2nd June 2006 \\ First published as an Advance Article on the web 19th June 2006 \\ DOI: $10.1039 / \mathrm{b} 604742 \mathrm{~d}$
}

\section{5-Aryl-2(5H)-furanones can be synthesized by the $\mathrm{Rh}$-catalyzed reactions of arylboronic acids with internal alkynes under a $\mathrm{CO}$ atmosphere.}

Since Hayashi et al. reported the first Rh-catalyzed addition of aryl- and alkenylboronic acids to $\alpha, \beta$-unsaturated ketones, ${ }^{1}$ the Rh-catalyzed addition of organoboron reagents to various unsaturated systems has become increasingly popular as a method of constructing $\mathrm{C}-\mathrm{C}$ bonds. Organoboron reagents readily undergo transmetallation with $\mathrm{Rh}$ to form arylrhodium(I) species that are capable of inducing the nucleophilic arylation of various electrophilic sites. ${ }^{1,2}$ It was also shown recently that the $\mathrm{Rh}$-catalyzed reaction of arylboronic acids with terminal $\alpha, \beta$ unsaturated ketones in a $\mathrm{CO}$ atmosphere yielded 1,4-diketones. ${ }^{3}$

In this paper, we present another example of the Rh-catalyzed reaction of arylboronic acids: a reaction of arylboronic acids with alkynes under a $\mathrm{CO}$ atmosphere to yield $2(5 \mathrm{H})$-furanones (2-butenolides).

Carbonylation of a phenylboronic acid and diphenyl acetylene mixture (in the ratio $3: 1)$ in the presence of $[\mathrm{RhCl}(\mathrm{COD})]_{2}(3 \%$ $\mathrm{Rh}$ ) in dioxane solvent under $20 \mathrm{~atm} \mathrm{CO}$ pressure at $120{ }^{\circ} \mathrm{C}$ for $16 \mathrm{~h}$ yielded 3,4,5-triphenylfuran-2(5H)-one (3a) as the major product, in addition to small amounts of 2,3-diphenyl- $1 H$-inden-1one (4a), 2,3-dihydro-2,3-diphenylinden-1-one (5a), and the $Z$ - and $E$-stereoisomers of 1,2,3-triphenylprop-2-ene-1-one (6a) carbonylation products (Scheme 1) (Table 1, entry 1) $\$$

A direct carbonylation product of phenylboronic acid, benzaldehyde, was also produced by the reaction in significant amounts ( $45 \mathrm{~mol} \%$ on the basis of the initial phenylboronic acid quantity). Addition of $\mathrm{PPh}_{3}$ ligand or $\mathrm{NEt}_{3}$ base to the reaction medium significantly reduced the formation of 3 a product (Table 1, entries 2 and 3). The reaction was observed to proceed less selectively in a

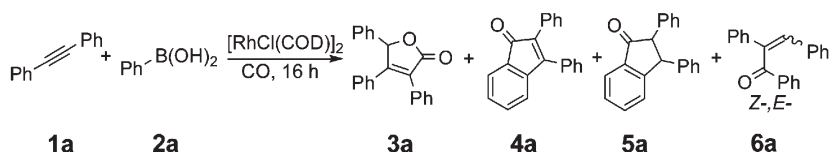

Scheme 1 Rhodium(I)-catalyzed carbonylative addition of phenylboronic acid to diphenylacetylene.

${ }^{a}$ Department of Chemistry, Faculty of Science, Izmir Institute of Technology,Urla35430,Izmir,Turkey.E-mail:leventartok@iyte.edu.tr; Fax: +90 232 7507509; Tel: +902327507529

${ }^{b}$ Department of Chemistry, Faculty of Science, Ege University, Bornova 35100, Izmir, Turkey

$\uparrow$ Electronic supplementary information (ESI) available: Description and NMR spectra of samples. dioxane-water $(9: 1)$ mixture (Table 1, entry 4$)$. The presence of water increased the formation of $\mathbf{4 a}, \mathbf{5 a}$ and $\mathbf{6 a}$ products, while formation of $\mathbf{3 a}$ was greatly reduced. Use of a pre-dried dioxane solvent (dried over the molecular sieve 4A) lessened the formation of benzaldehyde and $\mathbf{6 a}$ to trace amounts (Table 1, entry 5). However, the presence of $1 \mathrm{~g}$ of the molecular sieve $4 \mathrm{~A}$ in the reaction medium appeared to be detrimental to the efficiency and selectivity of the process (Table 1 , entry 6).

We postulate here a sequential insertion of $\mathrm{CO}$-alkyne-CO leading to the formation of $2(5 H)$-furanones (Scheme 2): It is generally accepted that an arylrhodium(I) species (A) is formed by the transmetallation of $\mathrm{Rh}(\mathrm{I})$ compounds with organoborons. ${ }^{2}$ The arylrhodium(I) could then insert into $\mathrm{CO}$ to give an aroylrhodium(I) species $(\mathbf{B})$, which then undergoes a 1,2-addition to the carbon-carbon triple bond. Insertion of the resulting $\beta$-aroyl alkenylrhodium(I) complex (C) into $\mathrm{CO}$, followed by a ring closure, could form a $\sigma$-furanoyl complex (D). Displacement of $\mathrm{Rh}$ from the cyclic complex by protonation leads to a 5-aryl$2(5 H)$-furanone molecule (3). ${ }^{4}$ The source of the proton should be mainly the arylboronic acid itself and its decomposition products.

The enhanced formation of benzaldehyde and other side products in moist dioxane could arise from a promoted hydrogen transfer in the form of $\mathrm{H}^{+}$or from a water-gas shift reaction.

The optimum reaction temperature was determined to be $80{ }^{\circ} \mathrm{C}$ (Table 1, entries 7 and 8). The formation of by-products was greatly reduced at this temperature. However, no activity was observed at $60{ }^{\circ} \mathrm{C}$ in dioxane solvent. Decreasing the $\mathrm{Rh}$ concentration to $1 \mathrm{~mol} \%$ on the basis of alkyne reduced the formation of 3a (Table 1, entry 9).

The reaction was more efficient for the formation of $\mathbf{3 a}$ when performed in dry toluene and the formation of other side products were minimized (Table 1, entry 10). Compared to dioxane, the smaller moisture content of toluene and its water immiscible nature is probably a significant factor in the diminution of the side reactions. The reaction also proceeded successfully in the case of a lower Rh concentration of $1 \%$ (Table 1, entry 11). Furthermore, the catalyst loading could also be lowered to $0.3 \% \mathrm{Rh}$ with only a small sacrifice in the product formation (Table 1, entry 12). In contrast to the reaction in dioxane, performing the reaction at $60{ }^{\circ} \mathrm{C}$ afforded a moderate 3a yield (Table 1 , entry 13). The method does not require large excesses of boronic acids, since the reaction was also remarkably effective at a phenylboronic acid : diphenyl acetylene ratio of 1.2 (Table 1, entry 14).

The synthesis of furan-2(5H)-ones (2-butenolides) are of great interest since some derivatives of these compounds occur naturally and possess significant biological activity. ${ }^{5}$ Numerous transition 
Table 1 Rhodium(I)-catalyzed reaction of phenylboronic acid and diphenyl acetylene under CO pressure ${ }^{a}$

\begin{tabular}{|c|c|c|c|c|c|c|c|c|c|}
\hline Entry & Solvent & $\mathrm{Rh}(\%)$ & $2 a: 1 a$ & $T /{ }^{\circ} \mathrm{C}$ & Conversion (\%) & 3a $(\%)^{b}$ & $4 \mathbf{a}(\%)^{b}$ & $\mathbf{5 a}(\%)^{b}$ & $\mathbf{6 a}(\%)^{b}$ \\
\hline 1 & Dioxane & 3 & 3 & 120 & $>99$ & 70 & 5 & 15 & 11 \\
\hline 2 & Dioxane $^{c}$ & 3 & 3 & 120 & $>99$ & 44 & 15 & 15 & $<1$ \\
\hline 3 & Dioxane $^{d}$ & 3 & 3 & 120 & $>99$ & 39 & 7 & 7 & $<1$ \\
\hline 4 & Dioxane- $-\mathrm{H}_{2} \mathrm{O}(9: 1)$ & 3 & 3 & 120 & $>99$ & 39 & 11 & 24 & 20 \\
\hline 5 & Dioxane $e^{e}$ & 3 & 3 & 120 & $>99$ & 74 & 4 & 9 & $<1$ \\
\hline 6 & Dioxane $^{e, f}$ & 3 & 3 & 120 & $>99$ & 43 & 9 & 16 & $<1$ \\
\hline 7 & Dioxane $e^{e}$ & 3 & 3 & 100 & $>99$ & 80 & 2 & 5 & $<1$ \\
\hline 8 & Dioxane $^{e}$ & 3 & 3 & 80 & $>99$ & 86 & 2 & 3 & 1 \\
\hline 9 & Dioxane $^{e}$ & 1 & 3 & 80 & 88 & 63 & 2 & 4 & 1 \\
\hline 10 & Toluene $^{e}$ & 3 & 3 & 80 & $>99$ & 90 & $<1$ & $<1$ & $<1$ \\
\hline 11 & Toluene $^{e}$ & 1 & 3 & 80 & $>99$ & 85 & 1 & $<1$ & $<1$ \\
\hline 12 & Toluene $^{e}$ & 0.3 & 3 & 80 & 95 & 81 & 2 & 1 & $<1$ \\
\hline 13 & Toluene $^{e}$ & 1 & 3 & 60 & 63 & 43 & $<1$ & $<1$ & $<1$ \\
\hline 14 & Toluene $^{e}$ & 1 & 1.2 & 80 & $>99$ & 89 (78) & 2 & 1 & $<1$ \\
\hline
\end{tabular}

${ }^{a}$ Reaction conditions: $1 \mathrm{mmol} \mathrm{1a}, 10 \mathrm{~mL}$ solvent, $20 \mathrm{~atm} \mathrm{CO}, 16 \mathrm{~h} .{ }^{b} \mathrm{GC}$ yield, isolated yield is given within parentheses. ${ }^{c}$ In the presence of 0.06 equiv. $\mathrm{PPh}_{3} .{ }^{d}$ In the presence of $2 \mathrm{mmol} \mathrm{NEt}_{3} .{ }^{e}$ Dried over molecular sieve $4 \mathrm{~A} .{ }^{f}$ In the presence of $1 \mathrm{~g}$ of molecular sieve $4 \mathrm{~A}$.

metal-catalyzed methods have been exploited for the synthesis of multi-functional lactones. These methods usually involve carbonylative or non-carbonylative cyclization of unsaturated reagents functionalized by hydroxyl or carboxyl groups and the cyclocarbonylation of acetylenes. ${ }^{6}$ The former methods usually suffer from the scarcity of the starting organic reagents, which require complicated synthetic routes. In contrast, alkynes are more readily available reagents.

There are only a few reports on the carbonylative synthesis of 5-aryl-substituted furanones in the literature. The $\mathrm{Pd}(\mathrm{II})$-catalyzed cyclocarbonylation of 3-aryl-1-propynes and iodoarenes or acyl chlorides, in the presence of $\mathrm{Pd}(\mathrm{OAc})_{2}(5 \mathrm{~mol} \%), \mathrm{PPh}_{3}$ ligand and $\mathrm{Et}_{3} \mathrm{~N}$ base under $\sim 20-80 \mathrm{~atm} \mathrm{CO}$ pressure, led to fair-to-good yields of $E$-3-arylbutenolides. ${ }^{7}$ The Rh-catalyzed cyclohydrocarbonylation of $\alpha$-keto alkynes ${ }^{4 c}$ and Ru-catalyzed cyclocarbonylation of allenyl alcohols ${ }^{8}$ yielded related multi-functional lactones. Negishi et al. employed two carbonylative methods in the synthesis of 5-arylated furanones. ${ }^{9}$ Good yields were obtained

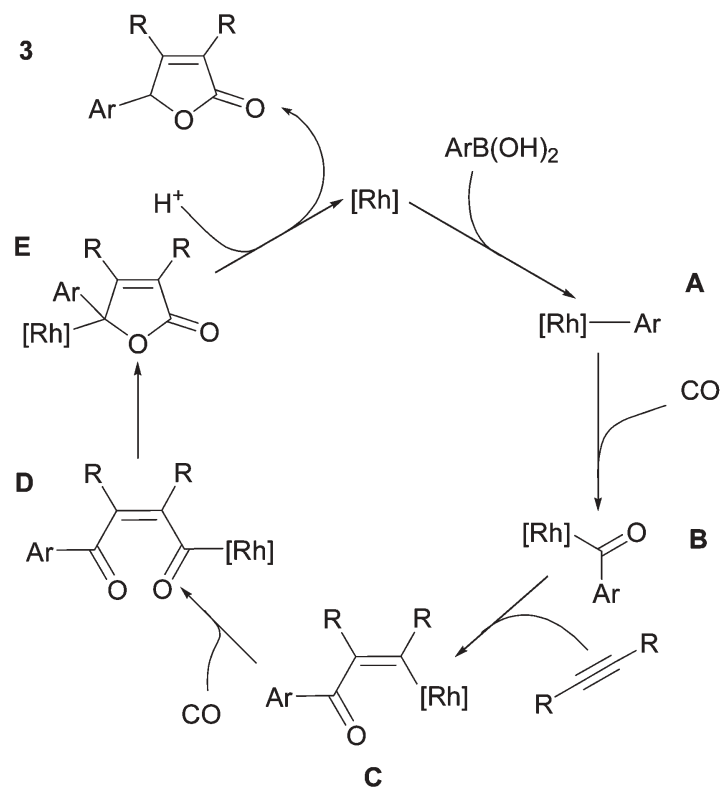

Scheme 2 Proposed mechanism for the carbonylative addition of boronic acids to alkynes. via carbonylation of $Z$ - $\beta$-iodoenones in the presence of $\mathrm{PdCl}_{2}\left(\mathrm{PPh}_{3}\right)_{2}$ catalyst and $\mathrm{Et}_{3} \mathrm{~N}$ base at $100-140{ }^{\circ} \mathrm{C}$, whereas a more direct method, the Pd-catalyzed carbonylative addition of aryl iodides to internal alkynes, proceeded less effectively, giving fair-to-moderate yields.

Our methodology was well applicable to para-substituted arylboronic acids (Table 2, entries 2-5) under the optimized conditions given above. Electron rich arylboronic acids were sufficiently reactive with diphenyl acetylene (Table 2, entries 2 and 3). Modest furanone product was recovered with an electron deficient arylboronic acid, 4-(trifluoromethyl)phenylboronic acid, at a $\mathrm{Rh}$ concentration of $1 \%$ (Table 2, entry 4), probably due to its poor ability to insert carbon monoxide. However, a higher yield for the corresponding furanone product succeeded at a $\mathrm{Rh}$ concentration of $3 \%$ (Table 2 , entry 5 ).

ortho-Tolylboronic acid failed in the carbonylative addition to diphenyl acetylene, probably owing to steric reasons. The alkyne conversion was about $50 \%$ with ortho-tolylboronic acid, and the reaction yielded 1-methyl-2-((E)-1,2-diphenylvinyl)benzene as the primary arylation product. It seems that although arylrhodium(I) species are capable of insertion into alkynes, the ortho-substituted aroylrhodium(I) intermediate was not reactive enough for the 1,2-addition to the carbon-carbon triple bond.

As an alkyl-substituted acetylene, 4-octyne also displayed high activity, providing a high furanone yield (Table 2, entry 6).

Table 2 Rhodium(I)-catalyzed reaction of arylboronic acid and alkynes under $\mathrm{CO}$ pressure

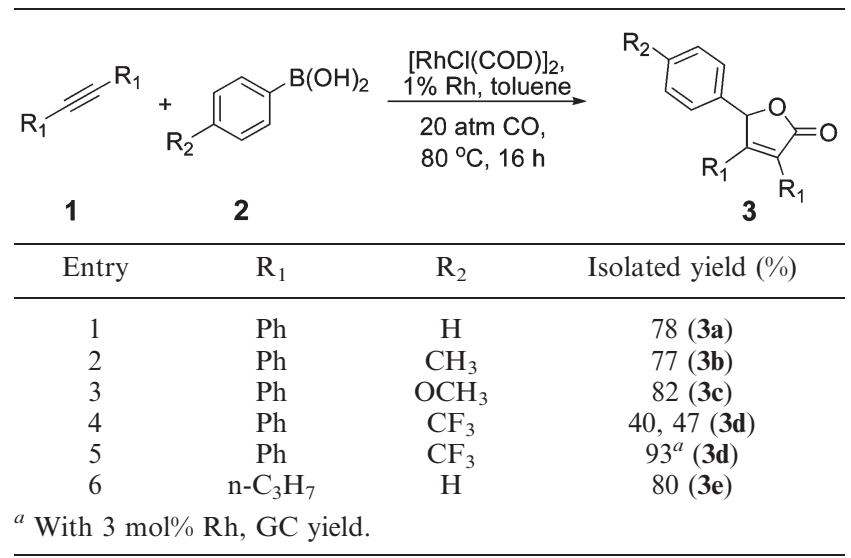


However, the method was unsuccessful with a terminal alkyne, phenyl acetylene, even though no acetylene substrate could be recovered at the end of the reaction. Here, the propensity of the terminal alkyne to undergo polymerization might have disfavored the carbonylation pathway.

In summary, the methodology established in this study proposes a relatively mild and simple way for the synthesis of 5-aryl substituted 2(5H)-furanones (2-butenolides). The application of the process to a variety of alkyne and organoboron reagents for the selective formation of other products, given in Scheme 1, and for other unsaturated systems, is under way to expand the scope of the methodology.

\section{Notes and references}

\$ Representative conditions for the synthesis of $\mathbf{3 a}$ (conditions of Table 1, entry 14): A mixture of alkyne $(1 \mathrm{mmol})$, arylboronic acid $(1 \mathrm{mmol})$, $[\mathrm{RhCl}(\mathrm{COD})]_{2}(0.005 \mathrm{mmol}, 1 \mathrm{~mol} \% \mathrm{Rh})$ and $10 \mathrm{~mL}$ toluene (pre-dried) was added into a $50 \mathrm{~mL}$ stainless steel autoclave with a glass insert tube. The sealed autoclave was then evacuated and purged twice successively with $10 \mathrm{~atm}$ CO. Subsequently, the reactor was pressurized to $20 \mathrm{~atm}$ with $\mathrm{CO}$ and the mixture stirred magnetically in a pre-heated oil bath. After cooling, the reaction mixture was recovered with ethyl acetate and extracted with a brine solution. The products were analyzed by GC and GC-MS and isolated by column chromatography.

1 M. Sakai, H. Hayashi and N. Miyaura, Organometallics, 1997, 16, 4229.

2 For reviews, see: (a) K. Fagnou and M. Lautens, Chem. Rev., 2003, 103, 169; (b) T. Hayashi and K. Yamasaki, Chem. Rev., 2003, 103, 2829. For recent examples, see: $(c)$ M. Sakai, M. Ueda and N. Miyaura, Angew. Chem., Int. Ed., 1998, 37, 3279; (d) K. Oguma, M. Miura, T. Satoh and
M. Nomura, J. Am. Chem. Soc., 2000, 122, 10464; (e) C. G. Frost and K. J. Wadsworth, Chem. Commun., 2001, 2316; ( $f$ ) M. Lautens, A. Roy, K. Fukuoka, K. Fagnou and B. Martín-Matute, J. Am. Chem. Soc., 2001, 123, 5358; $(g)$ T. Hayashi, K. Inoue, N. Taniguchi and M. Ogasawara, J. Am. Chem. Soc., 2001, 123, 9918; (h) K. Oguma, M. Miura, T. Satoh and M. Nomura, J. Organomet. Chem., 2002, 648, 297; (i) M. Lautens, C. Dockendorff, K. Fagnou and A. Malicki, Org. Lett., 2002, 4, 1311; (j) T. Matsuda, M. Makino and M. Murakami, Org. Lett., 2004, 6, 1257; ( $k$ ) T. Miura, M. Shimada and M. Murakami, Angew. Chem., Int. Ed., 2005, 44, 7598; (l) K. Ueura, T. Satoh and M. Miura, Org. Lett., 2005, 7, 2229; (m) R. Shintani, A. Tsurusaki, K. Okamoto and T. Hayashi, Angew. Chem., Int. Ed., 2005, 44, 3909; (n) R. Shintani, W.-L. Duan, T. Nagano, A. Okada and T. Hayashi, Angew. Chem., Int. Ed., 2005, 44, 4614.

3 M. Sauthier, Y. Castanet and A. Mortreux, Chem. Commun., 2004, 1520.

4 (a) T. Mise, P. Hong and H. Yamazaki, J. Org. Chem., 1983, 48, 238; (b) T. Joh, K. Doyama, K. Onitsuka, T. Shiohara and S. Takanashi, Organometallics, 1991, 10, 2493; (c) B. G. Van den Hoven, B. El Ali and H. Alper, J. Org. Chem., 2000, 65, 4131.

5 (a) Y. S. Rao, Chem. Rev., 1976, 76, 625; (b) G. V. Rao and R. B. Cain, J. Chem. Soc., Perkin Trans. 1, 1996, 2111; (c) S. Handa, Tetrahedron. Asymmetry, 1996, 7, 7565; (d) S. V. Ley, L. R. Cox and G. Meek, Chem. Rev., 1996, 96, 423; (e) E. Negishi and M. Kotora, Tetrahedron, 1997, 53, 6707; (f) Comprehensive Natural Products Chemistry, ed. D. H. R. Barton, K. Nakanishi and O. Meth-Cohn, Elsevier Science Ltd., Oxford, 1999, vol. 8, pp. 378-385.

6 For reviews, see: (a) B. El Ali and H. Alper, Synlett, 2000, 161; (b) S. S. Vizer, K. B. Yerzhanov, A. A. Al Quntar and V. M. Dembitsky, Tetrahedron, 2004, 60, 5499.

7 Y. Huang and H. Alper, J. Org. Chem., 1991, 56, 4534.

8 E. Yoneda, S.-W. Zhang, D.-Y. Zhou, K. Onitsuka and S. Takahashi, J. Org. Chem., 2003, 68, 8571.

9 C. Copéret, T. Sugihara, G. Wu, I. Shimoyama and E.-i. Negishi, J. Am. Chem. Soc., 1995, 117, 3422. 